\title{
So you want your research to be relevant? Building the bridge between ecosystem services research and practice
}

\author{
Lydia Olander $^{\mathrm{a}, *}$, Stephen Polasky ${ }^{\mathrm{b}}$, James S. Kagan ${ }^{\mathrm{c}}$, Robert J. Johnston ${ }^{\mathrm{d}}$, Lisa Wainger ${ }^{\mathrm{e}}$, David Saah ${ }^{\mathrm{f}}$, \\ Lynn Maguire $^{g}$, James Boyd ${ }^{\text {h,i }}$, David Yoskowitz ${ }^{\mathrm{j}}$
}

a Nicholas Institute for Environmental Policy Solutions and Nicholas School of the Environment, Duke University, Durham, NC, USA

${ }^{\mathrm{b}}$ Department of Applied Economics, University of Minnesota, St. Paul, MN, USA

${ }^{\mathrm{c}}$ Institute for Natural Resources, Oregon State University and Portland State University, Portland, OR, USA

${ }^{\mathrm{d}}$ Department of Economics and The George Perkins Marsh Institute, Clark University, Worcester, MA, USA

${ }^{\text {e } C h e s a p e a k e ~ B i o l o g i c a l ~ L a b o r a t o r y, ~ U n i v e r s i t y ~ o f ~ M a r y l a n d ~ C e n t e r ~ f o r ~ E n v i r o n m e n t a l ~ S c i e n c e, ~ S o l o m o n s, ~ M D, ~ U S A ~}$

${ }^{\mathrm{f}}$ Geospatial Analysis Lab, University of San Francisco, and SIG GIS, San Francisco, CA, USA

${ }^{\mathrm{g}}$ Nicholas School of the Environment, Duke University, Durham, NC, USA

${ }^{\mathrm{h}}$ Center for the Management of Ecological Wealth, Resources for the Future, Washington, DC, USA

${ }^{\mathrm{i}}$ National Socio-Environmental Synthesis Center, Annapolis, MD, USA

${ }^{\mathrm{j}}$ Harte Research Institute, Texas A\&M University, Corpus Christi, TX, USA

\section{A R T I C L E I N F O}

\section{Article history:}

Received 14 November 2016

Received in revised form 7 April 2017

Accepted 6 June 2017

Available online 4 July 2017

\section{Keywords:}

Natural capital

Ecosystem models

Practitioner-focused research

Co-production

\begin{abstract}
A B S T R A C T
There is growing demand for information regarding the impacts of decisions on ecosystem services and human benefits. Despite the large and growing quantity of published ecosystem services research, there remains a substantial gap between this research and the information required to support decisions. Research often provides models and tools that do not fully link social and ecological systems; are too complex, specialized, and costly to use; and are targeted to outcomes that differ from those needed by decision makers. Decision makers require cost-effective, straightforward, transferable, scalable, meaningful, and defensible methods that can be readily understood. We provide illustrative examples of these gaps between research and practice and describe how researchers can make their work relevant to decision makers by using Benefit Relevant Indicators (BRIs) and choosing models appropriate for particular decision contexts. We use examples primarily from the United States, including cases that illustrate varying degrees of success in closing these gaps. We include a discussion of the challenges and opportunities researchers face in adapting their work to meet the needs of practitioners.
\end{abstract}

(c) 2017 Elsevier B.V. All rights reserved.

\section{Contents}



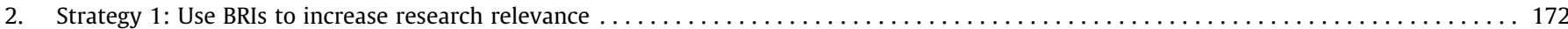

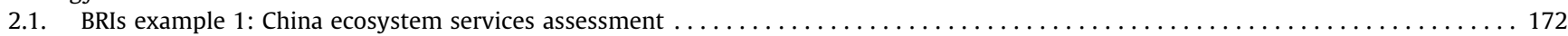



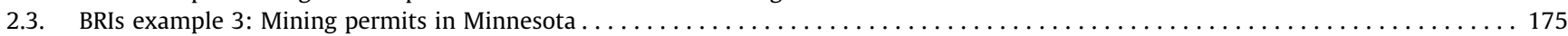

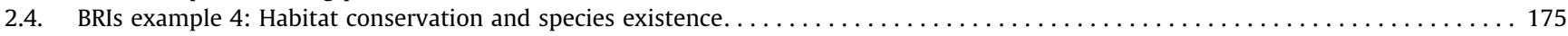

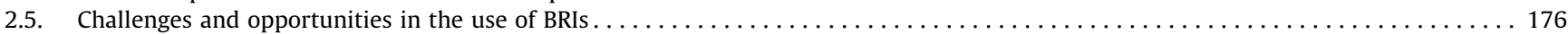

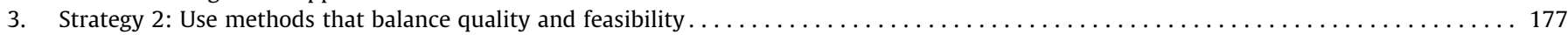

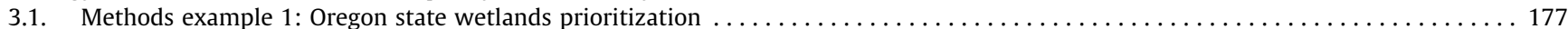

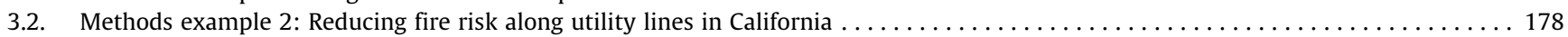

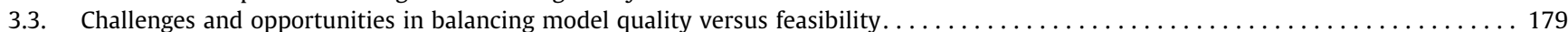

\footnotetext{
* Corresponding author.

E-mail addresses: Lydia.olander@duke.edu (L. Olander), Polasky@umn.edu (S. Polasky), jkagan@pdx.edu (J.S. Kagan), rjohnston@clarku.edu (R.J. Johnston), wainger@umces. edu (L. Wainger), dssaah@usfca.edu (D. Saah), lmaguire@duke.edu (L. Maguire), boyd@rff.org (J. Boyd), David.Yoskowitz@tamucc.edu (D. Yoskowitz).
} 


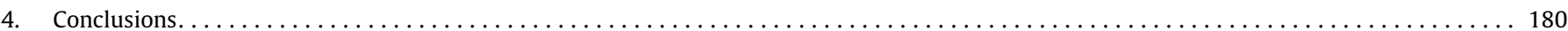

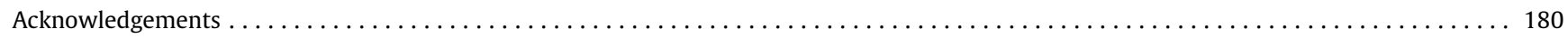



\section{Research that meets practitioner needs}

Evaluating the impact of public and private decisions on natural capital and ecosystems is an increasing focus of public and private decision-makers, including government and business leaders (e.g., The Declaration, 2012; WAVES| Wealth Accounting and the Valuation of Ecosystem Services, 2016; EOP, 2015; IPBES| Intergovernmental Platform on Biodiversity and Ecosystem Services, 2016). Practitioners in both the public and private sectors are motivated to incorporate the value of ecosystem services in decisions affecting issues such as land management (e.g., Bateman et al., 2013; Johnston et al., 2014; Lawler et al., 2014; Ouyang et al., 2016; National Ecosystem Services Partnership, 2016), pollution control (TEEB, 2012), natural resource supply (Reddy et al., 2015), rural/agricultural policy (Ribaudo et al., 2010; Bauer and Johnston, 2013), and coastal/marine management (Holland et al., 2010; Barbier et al., 2011; Lipton et al., 2014), but often lack the capacity to do so. This focus has led to a growing demand for applicable tools to assess the impacts of decisions on ecosystem services and human benefits (PCAST, 2011).

At the same time there has been tremendous growth in scholarly research on ecosystem services. A Google Scholar search finds almost 5 times as many publications using the key word "ecosystem services" in this decade compared to last (Google Scholar Search, 2016). One might assume that this increasing "supply" of ecosystem services research would meet the increasing demand for ecosystem services information. Yet despite the large and growing quantity of published ecosystem services research and the desire of many decision-makers to account for natural capital and ecosystem service impacts, there remains a substantial gap between academic research and the informational needs of decision-makers and practitioners (Guerry et al., 2015; Hanley et al., 2015; Ruckelshaus et al., 2015; Braat, 2015; Carpenter et al., 2009).

Why is ecosystem services research not meeting the needs of decision-makers? Over the last 4 years, US federal agency scientists and decision-makers involved with the National Ecosystem Services Partnership (NESP) have described multiple factors that inhibit the use of ecosystem services assessments and valuations produced by the research community (see NESP, 2016). Similar factors have been described by recent advisory boards and others commenting on the use of ecosystem services analysis within US federal agencies (e.g., US EPA, 2009; NOAA SAB, 2016), and by advisory groups in other regions of the world (Braat, 2015; Wong et al., 2015). These factors fall into two primary groups. The first group comprises factors related to failure to develop transparent and unambiguous linkages between ecosystem changes and outcomes that matter to or are directly valued by people. For example:

- Available biophysical models tend to focus on purely ecological or biophysical outcomes not clearly or directly linked to outcomes that matter to people (Keeler et al., 2012; Schultz et al., 2012; Olander et al., 2015).

- Available economic and social science models capable of estimating the value of ecosystem services are often not well linked with biophysical models or their outputs (Johnston et al., 2012; Schultz et al., 2012).

- The results of studies that generate estimates of the total value of ecosystem services (e.g. Costanza et al., 1997) are not capable of estimating changes in the value of these services arising from many types of changes in policy or management, nor do they fully capture location-specific for ecological or socio-economic factors that determine value.

- Research from the academic community often fails to address topics or ecosystem services directly relevant to organizational decision-making or ignores constraints (e.g., statutory restrictions, data requirements) that are directly relevant to the effects of decisions on ecosystem services or values (Schaefer et al., 2015).

The second set of reasons for the disconnect between available research and decision-maker needs is related to the use of methods that do not answer relevant policy and management questions, and/or are not sufficiently transparent, usable and generalizable by decision-makers, considering factors such as budget, time, capacity, and data constraints. For example:

- Models provided to predict the ecological consequences of decisions and the value of affected services require expertise that agencies often lack, particularly in economics and other social sciences.

- The data required by most ecosystem service models are too costly to acquire (e.g., in time, money, resources, required approvals).

- The results of high quality studies are often so detailed and specialized that they are difficult to generalize and therefore of limited relevance for policy or management questions.

- Valuation methods advocated by researchers (e.g., stated preference methods) may not be readily accepted by agencies overseeing research and data collection (e.g., Office of Management and Budget), or may require extensive and time-consuming approvals (Griffiths and Wheeler, 2005).

- The accuracy and reliability of ecological and social models, and the uncertainty associated with results, are often unknown.

There are also reasons why researchers frequently lack incentives to produce relevant research that fits the needs of practitioners. Publication pressures may incentivize researchers to work on projects with greater novelty and precision rather than those relevant to decision-making. Conducting relevant research can also be time consuming. It often requires extensive interactions with stakeholders and the dedication of time to understand specific policy and management contexts. This time cost can be a disincentive for researchers to engage in truly relevant research.

This article is geared to researchers who, despite the challenges raised in the prior paragraph, want to pursue research that meets the needs of those making policy and management decisions. To this end, we suggest and illustrate two key strategies that are designed to improve researchers' ability to produce research that is directly relevant to practice. These strategies reflect approaches that have proven successful in integrating ecosystem services research to decision-making.

The first strategy is to design research methods that go beyond biophysical outcomes (e.g., water storage) to provide clearly linked ecological and social outcomes of interest (e.g., amount and timing of water available for a specific user). We refer to these outcomes as benefit-relevant indicators (BRIs). BRIs have characteristics which make them particularly well suited to informing decisions and supporting any subsequent valuation efforts (Olander et al., 2015). The 
second strategy is to develop research methods that are explicitly designed to meet the needs of decision-makers. These needs often include the development or application of research tools and methods that are not overly complex, that reflect the capacity (e.g., expertise, funding, etc.) available to decision-makers, and that address the specific informational needs of each decision-context (e.g., provide results at necessary levels of certainty and precision). We illustrate these two strategies using examples that draw on our collective experience advising government agencies on natural resource management primarily in the United States. However, the proposed framework is designed for broader application and relevant to other research and practitioner communities.

\section{Strategy 1: Use BRIs to increase research relevance}

Ecosystem service research often lacks complete analysis that links policy or management actions to human benefits (Wainger and Mazzotta, 2011). Producing ecosystem services research that meets decision makers' needs depends on the extent to which the research addresses outcomes that are both valued by people and relevant to organizational decision-making (Boyd et al., 2016). This goal can be achieved by reporting results of ecological or biophysical modeling using benefit-relevant indicators (BRIs) that are directly salient to decisions of an identified group of practitioners. BRIs are well-defined measures of "things valued by people. . .because they have a direct causal impact on human welfare" (Olander et al., 2015). BRIs are the link between ecological measures and values or preference assessment. They reflect both the ecological supply and the social demand for an ecosystem service. BRIs may be measured in a variety of units, depending on the ecosystem service in question (Abt Associates, 2015).

The complete bridge from policy or management action to benefits requires models that establish a link between actions and ecological conditions, and then from ecological conditions to ecosystem services measured in terms of BRIs (Fig. 1). In some cases, it may also be desirable to translate BRIs into benefits monetary or non-monetary expressions of value (the final link in Fig. 1). But in other cases it may be sufficient to stop with BRIs (Olander et al., 2015). BRIs can at least partially capture potential social demand or values. A simple example would be a projected change in recreational fish stocks in water bodies used by anglers (or changes in expected catch per unit effort), weighted by the current recreational usage of each water body (to reflect the number of anglers that might benefit from fish stock improvements in each location, assuming that the number of anglers remains approximately constant). If, however, subsequent valuation is to be conducted, BRIs need not directly reflect the potential extent of demand or value as demand or value will be measured during the valuation stage. An example of the latter type of BRI would simply be a projected change in recreational fish stocks in water bodies used by anglers (or changes in expected catch per unit effort).

Regardless of the BRI used, integrated biophysical and socioeconomic information is required. Insufficient linkage between biophysical and socio-economic analysis has led to estimates of ecosystem service value with ambiguous interpretation and valid- ity (Blamey et al., 2002; Boyd and Krupnick, 2013; Boyd et al., 2016; Johnston et al., 2012; Schultz et al., 2012).

The examples below illustrate various degrees of success in generating BRIs, and the challenges that can be encountered when moving along the causal chain illustrated in Fig. 1. The first two examples (China Ecosystem Services Assessment and Oregon Wetlands) illustrate cases in which simple quantification of BRIs was possible. A subsequent example illustrates a case in which BRIs cannot be calculated, because we lack the basic science to connect ecological changes to BRIs (Minnesota Mining). A related challenge illustrated by the Minnesota mining case is that the regulatory context establishes a standard measured in terms of an endpoint (pre-established toxin levels), without considering outcomes that matter to people (BRIs). In contexts such as this-with a disconnect between regulatory mandates and ecosystem services information-the role of ecosystem services research itself can be ambiguous for regulators (NOAA SAB, 2016), however, it may be quite important for local decision makers to have better information on impacts to people. The final illustration (Pygmy rabbit in North America) returns to an example in which BRIs can be calculated, and are particularly useful as a means to quantify valued outcomes when explicit expressions of value are not feasible or desired. Taken together, these examples are designed to illustrate relationships between the ways that researchers quantify ecosystem service impacts (ideally using BRIs), the type of information required by decision-makers in different situations, and the relevance of the research.

\subsection{BRIs example 1: China ecosystem services assessment}

In response to severe flooding along the Yangtze River in 1998 that caused major loss of life and property damage, China began several large ecosystem conservation and restoration programs, the Natural Forest Conservation Program and the Sloping Land Conversion Program. In 2012, China's Ministry of Environmental Protection and the Chinese Academy of Sciences launched China's first national-scale ecosystem assessment. The assessment was undertaken to both learn about the performance of past investments in conservation and to better target the next generation of conservation investments (Ouyang et al., 2016).

The assessment collected data on seven important endpoints of interest to the government of China: food production, carbon sequestration, soil retention, sandstorm prevention, water supply, flood mitigation, and habitat provision for biodiversity. Several of these endpoints are directly related to risk mitigation (e.g., sandstorm prevention and flood mitigation) while other endpoints are important for securing outcomes used continuously by humans (food production and water supply). Soil retention is important both for maintaining future soil productivity as well as improving downstream water quality. China also seeks to conserve its biodiversity that includes many endemic species by maintaining habitat, and to reduce net emissions of greenhouse gases through carbon sequestration. The assessment used extensive biophysical data collected in China, including digital elevation maps, hydrological records, satellite images of land cover, field surveys on biodiversity and soil erosion, and government records on

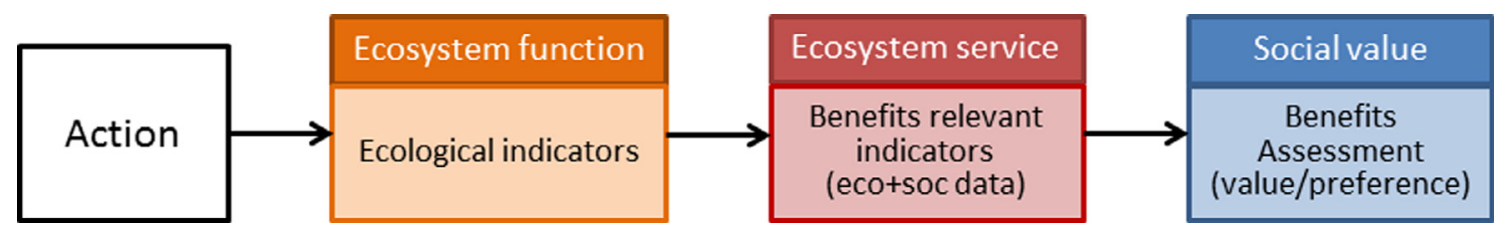

Fig. 1. Sequence of methods and information necessary for assessing ecosystem services. 
agricultural production. Using the InVEST model (Sharp et al., 2015), these data were used to generate ecological production functions and to show how the seven endpoints of interest changed between 2000 and 2010 based on changes in land use and land cover in China (Fig. 2). The results of the biophysical models were transformed into BRIs by intersecting the biophysical model results with the population potentially impacted by the changes. For example, the improvement in sandstorm prevention was assessed by calculating the tonnage of reduction in windborne erosion weighted by the population downwind.

The assessment was successful in delivering information about the endpoints of interest to decision-makers, and in many cases directly relevant to human beneficiaries (e.g., people potentially harmed by sandstorms). This outcome occurred largely because of the close relationship between decision makers in the Ministry of Environmental Protection and researchers in the Chinese Academy of Sciences. The close coordination between end users and researchers ensured that the assessment was designed to use the endpoints of interest (Fig. 2) and that data collection and modeling were directed towards delivering information about those endpoints (Ouyang et al., 2016).

\subsection{BRIs example 2: Oregon state prioritization of wetlands for mitigation}

In the state of Oregon, USA, managers used ecosystem services to help prioritize wetland conservation, mitigation and restoration (Oregon Wetland Rapid Assessment Protocol, ORWAP, Adamus et al., 2010). Wetland managers were required to prioritize wetland restoration and protection in order to comply with federal and state clean water regulations. Those regulations require that when wetland impacts cannot be avoided, they must be mitigated through restoration or permanent protection of other wetlands.

Wetland mitigation in Oregon had been based on the replacement of each lost acre with an acre either restored or protected from alteration. This approach does not guarantee that equivalent ecosystem services or benefits will be replaced, as different wetlands in different areas may provide different services
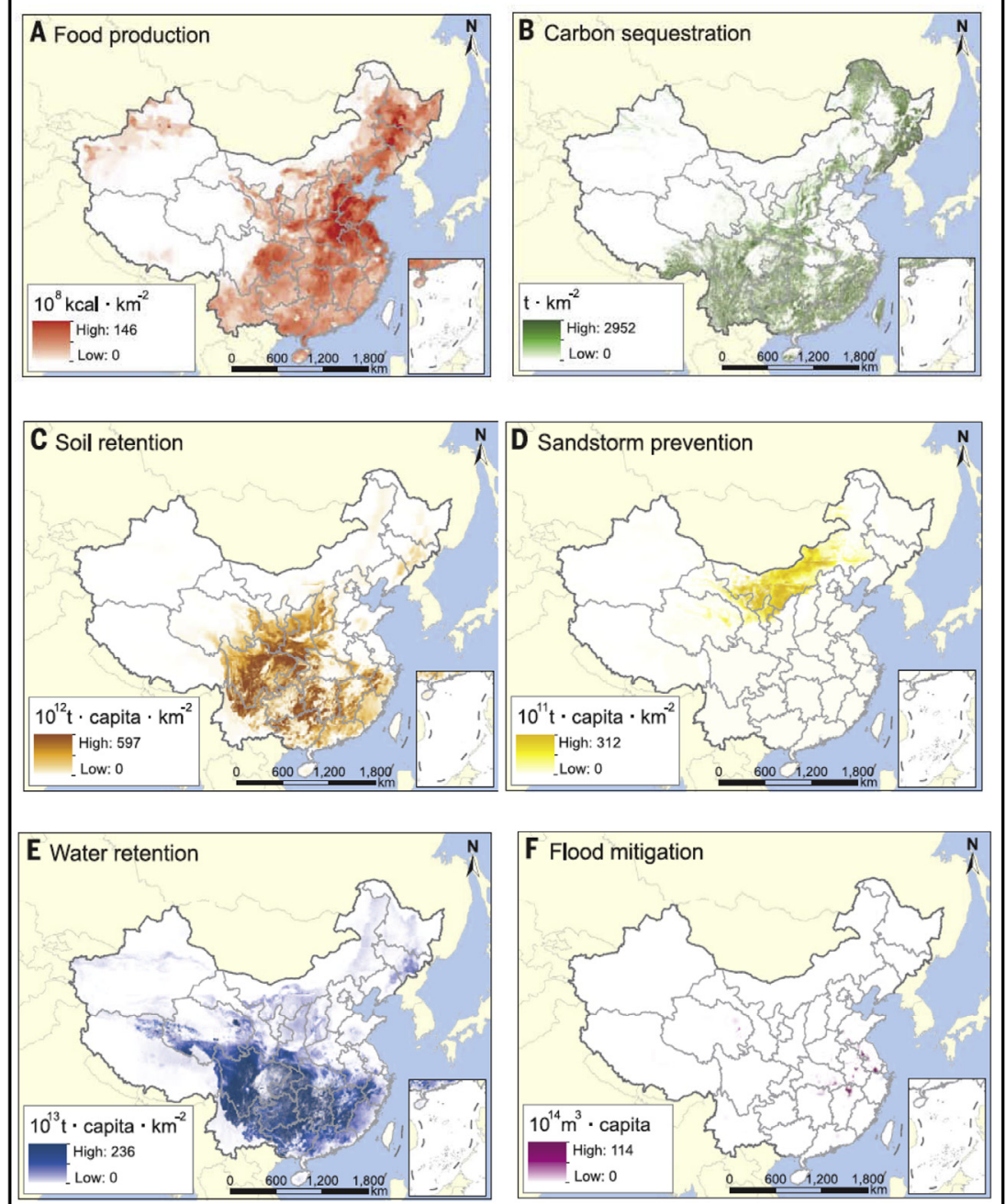

Source: Ouyang et al. 2016. Science.

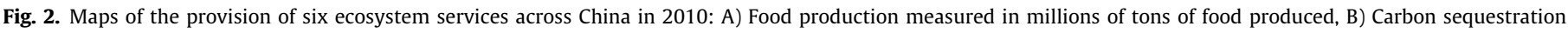

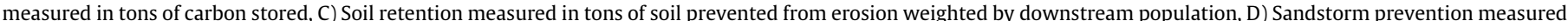

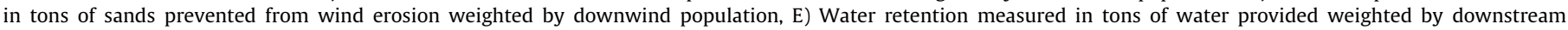
population, and F) Flood mitigation measured the storage capacity of wetlands, lakes and reservoirs in cubic meters weighted by downstream population. 


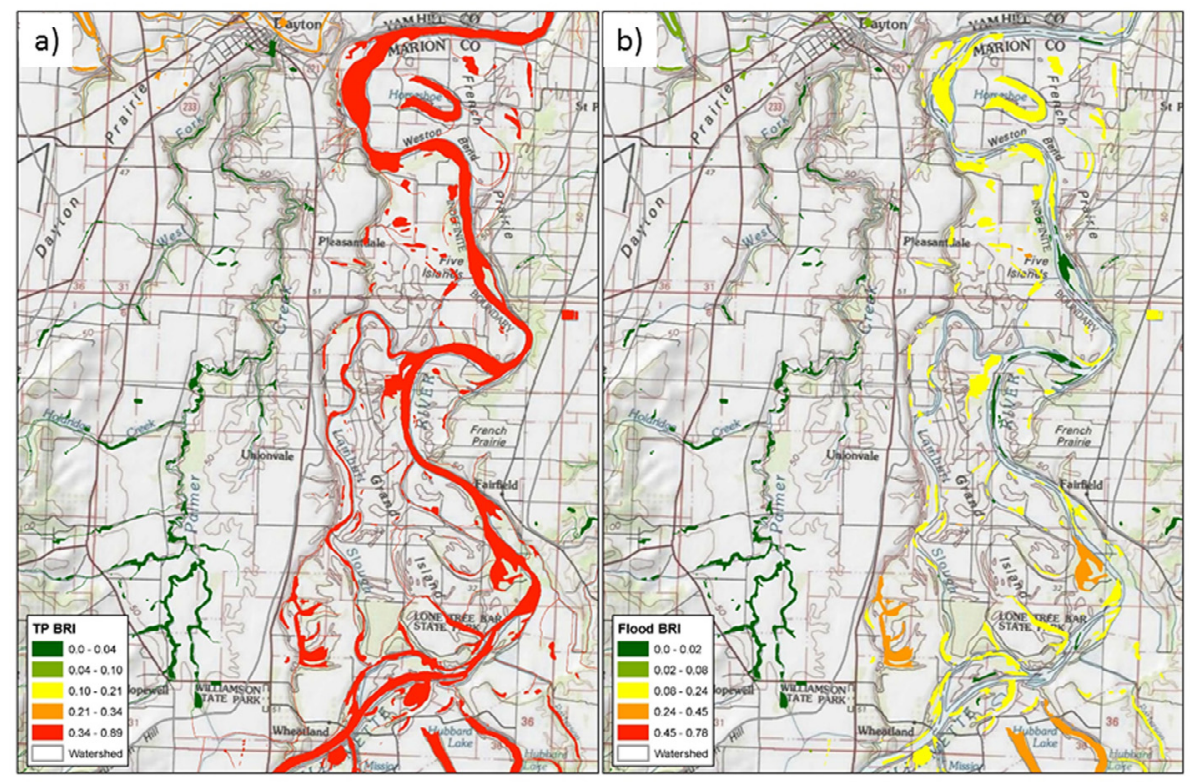

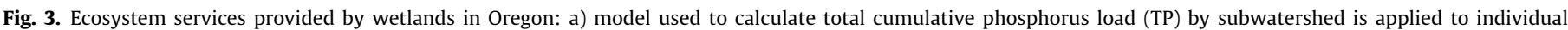

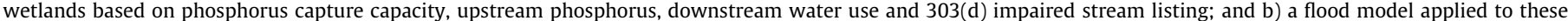

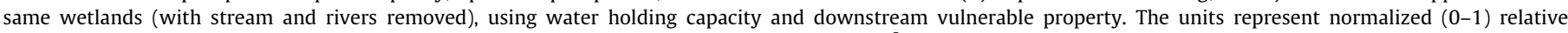

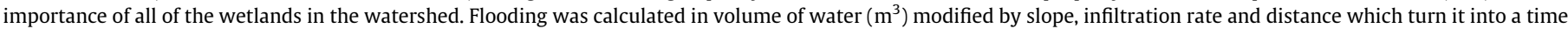
of concentration (TC). Phosphorus was calculated in $\mathrm{kg}$ using unit loads ( $\mathrm{kg} / \mathrm{km}^{2} / \mathrm{year}$ ) modified by upstream contributing area and downstream uses.

(or quantities of the same services). Responding to this problem, the regulatory community determined that the most important wetland services included property damage protection (due to flood risk reduction), late season water provision and temperature control, and support for recreational activities or species conservation via provisioning of habitat, food, water, and refugia (Adamus et al., 2010). To assess changes in these services, Oregon wetland managers created a functional assessment inventory tool to measure wetland functions, such as water temperature moderation, water holding capacity, groundwater recharge, and wildlife support; and are developing rules to use these functional values in defining mitigation needs.

In 2013, the US Environmental Protection Agency (EPA) funded a project to allow a team at Oregon State University to map and model these functions in a way that more closely links them to the beneficiaries that appreciate and use the ecosystem services that each wetland provides. The goal was to use these maps and models to prioritize mitigation sites based on the services they likely provide, rather than assuming all wetlands provide services equally with provision being a function of wetland size alone. Fig. 3 shows how wetlands important for capturing phosphorus loads into impaired waters are different from those important for storage capacity to reduce flooding of property.

The study first determined ways to estimate functional measures such as the wetlands' inherent ability to hold water using available spatial data such as soil composition and depth, wetland size, slope, and the distance wetlands are from streams and floodplains. Other attributes, such as shading or forest cover of the wetlands, can be used to estimate a wetland's ability to benefit fish, while the type of vegetation present can be used to model the capacity to remove unwanted phosphorus or nitrogen. All of these, however, are measures of wetland function which may or may not provide valued services, depending on how the provision of service links to the need or demand for such services in particular areas. Thus, additional data on demand are needed to generate BRIs. For example data on the location of streams impaired by high nitrogen or phosphorus loads and the number of downstream drinking water facilities were used to indicate demand for nutrient capture and storage in wetlands, and data on the areas of developed properties at risk of flooding was used to indicate the demand for flood reduction. Simply adding an evaluation of what services communities need creates the bridge to ecosystem services.

Subsequent transformation of these purely biophysical measures into BRIs - measures that capture both ecological function and human demand (or at least potential human use)-clarifies the relevance of restoration and mitigation for valued ecosystem services. Here, the primary difference between functional measures and BRIs is the inclusion of information on spatial location relative to beneficiaries, which is essential to understand the demand for various services. For example, in the Roberts Creek watershed of Oregon, functions related to hydrology (e.g., water holding capacity and groundwater recharge) providing flood control and late season water provision are of little value, as the area is very rural (few beneficiaries), and none of the affected communities (the small towns of Drain, Elkton and Reedsport) have experienced any flood damage or late season water shortages over the last 40 years. However, the watershed is exceptionally important to the large but declining salmon runs, and the ability of wetlands to support salmon is much more important in this particular location. Hence, measures of salmon support, such as cooling, reducing sediment or provision of wood or habitat reflect relevant BRIs in this area, but measures of hydrological functions not related to salmon habitat do not. Different services are valued in other Oregon watersheds. In the Tualatin watershed ${ }^{1}$, for example, salmon populations are not nearly as important, but the watershed includes a large amount of valuable property that frequently floods. Hence, flood control is one of the most important wetland services to local decision makers.

Similar linkages between wetland functions and BRIs can be established in the upper Klamath Basin, where salmon are no longer present, but the local tribe has been working with the U.S. Fish and Wildlife Service to recover two important resident fish, the Lost River sucker and the shortnose sucker. These species were

\footnotetext{
1 This watershed includes the large towns of Hillsboro and Beaverton which make up the western portion of the Portland Metropolitan Area.
} 
previously important food sources for the tribe, but are now listed as threatened species. Farmers in this watershed have also had insufficient water to support their crops, creating local conflicts over water (particularly late in the summer). Therefore, in this area, wetlands that provided late season water are more important to the community than wetlands better at providing flood support or cooling to support salmon.

BRIs can provide a practical way for decision makers to incorporate ecosystem services into their wetland restoration and mitigation rules and priorities, and hence promote actions that better serve affected human populations. However, to develop these measures, wetland functional assessments must be integrated with measures (or proxies) of the demand for individual wetland services. This was done in the Oregon project using a large number of untested, although seemingly reasonable assumptions. However, research is needed to validate these assumptions, and to establish more clear and defensible links between wetland functions and the provision of valued ecosystem services that can be generalized across jurisdictions and scales (i.e., county, watershed, state).

\subsection{BRIs example 3: Mining permits in Minnesota}

The prior examples illustrate cases in which the primary information required to translate ecological functions into BRIs was geospatial and contextual-related to the presence of beneficiaries and the relative demand for particular services in particular areas. In such cases, the link from functions to services can often be easily established, thereby increasing the relevance of ecosystem services research. However, in other cases, gaps in scientific knowledge prevent the establishment of these links without significant (and costly) additional work. An example of such a situation is found in the case of proposed mining permits in Minnesota. PolyMet Mining, Inc. has proposed building and operating a copper nickel mine in northern Minnesota.

As part of the permitting process, PolyMet completed an Environmental Impact Statement (EIS), which was approved by the state in 2016. The EIS is thousands of pages long and required more than a decade to complete. However, to begin operation Polymet must still obtain federal and state permits governing water and air quality and wetland protection. The decision to issue mining permits rests on whether statutory requirements are met, not on a diverse set of impacts to ecosystem services. Yet whether allowing the mine to operate is in the public interest or not depends, at least in part, on how mining operations will impact ecosystem services, including potential impacts on drinking water supplies, fishing and other water-based recreation, wild rice harvesting, habitat for species of concern, and air quality (Goodkind et al., 2013).

Although the EIS contains a wealth of information, it does not provide information on impacts to BRIs related to water quality such as drinking water supplies, fishing and other water-based recreation, and wild rice harvesting. The EIS predicts likely concentrations of contaminants such as toxic metals in water bodies near and downstream of the mine. It is relatively straightforward to use this information to estimate the probability that mining operations will violate water quality standards, but much more difficult to evaluate how such violations impact BRIs. For example, how would mining operations (and the resulting toxin releases) affect the safety of fish for consumption or fish abundance?

Completing the causal chain from the initial action (e.g., mining operations) to a recreational fishing BRI would begin with concentrations of pollutants as discussed in the EIS. However, it would also require additional information not supplied by the EIS, such as how pollutants are taken up in the aquatic food chain and concentrated in fish, the health impacts of eating fish contaminated at those levels, and likelihood of human exposure based on common patterns of recreational use. Ideally, the analysis would also include potential substitutes to fishing in affected waters and potential behavioral responses by recreational anglers to information about water quality and pollutant concentrations in fish. Some information gaps could be filled in using existing data and methods (e.g., patterns of recreational use) but some gaps are research frontiers (e.g., the fate and transport of metals in the environment and bio-concentration in aquatic species) that are largely unknown at present. In assessing the impacts of mining on water-related ecosystem services, researchers are far from developing the ecological production functions necessary to get to the BRIs of interest, and thus cannot provide what practitioners need in terms of measuring the environmental costs of proposed mining operations. Cases such as this provide substantial impediments to relevant ecosystem services research-as estimating the link between actions and human benefits requires science that is not readily available (or has not yet been developed).

\subsection{BRIs example 4: Habitat conservation and species existence}

In other cases, the science necessary to link actions to functions to BRIs is sufficiently developed, but the policy context is such that proceeding to valuation is either infeasible or unwanted by decision-makers. In such cases, BRIs themselves serve as an important final step in ecosystem services research. Situations such as this can sometimes arise in cases involving rare species preservation, where the primary human benefits derive from nonuse values (Wallmo and Lew, 2011). The pygmy rabbit (Brachylagus idahoensis), is a sagebrush obligate species from western North America of conservation concern due to declining sagebrush habitat. To date, the pygmy rabbit has not been listed under the U.S. Endangered Species Act, and the U.S. Fish and Wildlife Service believes that conservation efforts underway to protect the greater sagegrouse (Centrocercus urophasianus) will reduce the threats and help assure the pygmy rabbit's survival. However, the preferred habitat of these two species is not entirely overlapping, suggesting that some effort focused specifically on the pygmy rabbit may be required (Larruca and Brussard, 2008).

Habitat for the pygmy rabbit can be well-characterized, modeled and mapped. Relatively simple methods can provide reliable estimates of habitat suitability (Loiselle et al., 2003), and there are more complex models as well (Merow et al., 2014). BRIs associated with quantitative measures of population viability or similar indicators can be readily defined, and have been previously linked to values for other types of species (Johnston et al., 2012; Schultz et al., 2012). However, practical challenges can arise when seeking to extend beyond BRIs to incorporate people's preferences and values for this species because social values for this species are comprised almost entirely of nonuse values (such as existence and bequest values). The pygmy rabbit is small, found in very remote areas, and rarely seen outside of zoos. Yet, many people who look at even a few images of the species (Fig. 4) feel the species merits protection, even if they never have a chance to see it in the wild. The method traditionally used for assessing existence value in monetary terms is a stated preference survey (Bateman et al., 2002); such methods are commonly used to evaluate willingness to pay (WTP) for the preservation of rare and often unfamiliar species (Wallmo and Lew, 2011). However stated preference methods can be controversial and are accepted by many but not all decision makers. Various non-monetary measures of existence value might be developed, but these measures cannot be incorporated into benefit cost analysis or other formal evaluations that rely on monetary valuations. Researchers have recently developed best practice guidelines for stated preference to help promote more universal acceptance by decision-makers (Johnston et al., 2017). However, it remains likely that valuation metrics (from any method) will 


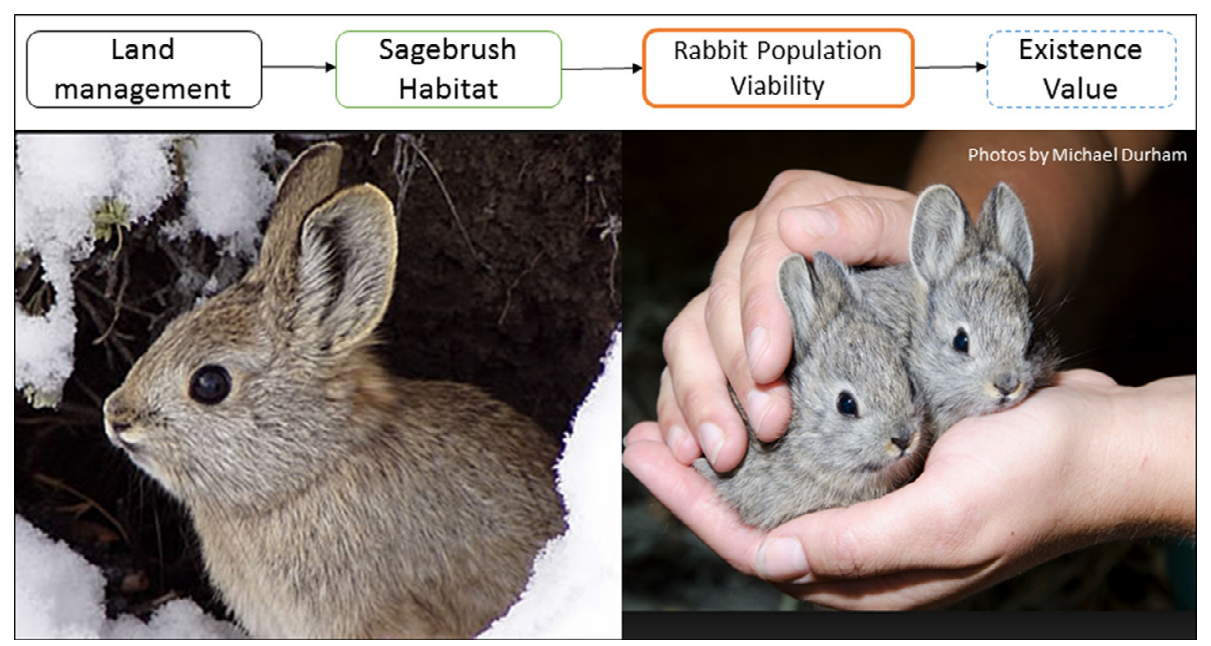

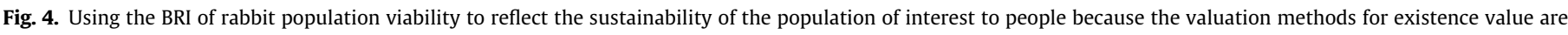
unacceptable to decision makers.

not always be accepted, highlighting the direct relevance of BRIs for rare species such as population viability measures. In such cases, relevant analysis requires a link between actions and BRIs, but stops at the BRI (i.e., the analysis does not continue to valuation; Fig. 4).

\subsection{Challenges and opportunities in the use of BRIs}

There is often at least one missing link in the causal chain from actions to changes in ecological conditions to changes in ecosystem services, leading to a failure to define outcomes in terms of BRIs (Holmes et al., 2004; Keeler et al., 2012; Johnston et al., 2013; Ruckelshaus et al., 2015). For example, in the mining illustration above, information on the concentration of contaminants could not be linked to implications for fishing, wild rice harvests, and other water related benefits. The causes of gaps are many and include a lack of monitoring of ecological outcomes that are relevant to people (e.g., fish abundance, toxin levels in edible fish), a lack of necessary models (e.g., on how toxins bioaccumulate), or a lack of data on human uses or potential demand (e.g., where people use affected resources). Alternatively, such information may be available but the link to human benefits is lacking (e.g., we know the toxin levels in fish but we don't know the effect this has on human health). Researchers can extend analysis beyond typical endpoints to help fill these gaps and move toward more meaningful benefit-relevant endpoints.

An example of a case with multiple missing links is that of forests and fire. In the US, more than a century of fire suppression and logging practices in low and middle elevation conifer forests of the Sierra Nevada have led to a landscape of high density forests dominated by small trees that are prone to significant wildfires (Miller et al., 2009). Fuels reduction, including forest thinning and prescribed fire, can be an effective means of reducing the risk of significant fires (Hurteau et al., 2009; Ager et al., 2010; Syphard et al., 2011). Various planning efforts to mitigate ecosystem service losses due to significant wildfires are being initiated (Wildland Fire Leadership Council, 2011) but links between avoided wildfire measures and some ecological co-benefits are still weak. Evaluating and measuring links between management, vegetation conditions and fire risk, or other important services from western coniferous forests such as wood products, wildlife habitat, and carbon storage has been demonstrated (Halofsky et al., 2014). Yet for these same forests, methods to measures impacts of fire or management on how and where forests provide water to the farmers, cities, and anglers downstream remain poorly understood. The hydrologic studies that explore this (Wondzell et al., 2007) require local hydrologic attributions that put them out of reach for managers. Other tools which might help (e.g., Benda et al., 2016) are proprietary, which also limits accessibility for many managers. As a result, hydrologic outputs are often ignored in evaluating different land management alternatives.

Despite challenges such as these illustrated in the examples above, a growing number of studies have fully connected ecological conditions to ecosystem services measured in terms of BRIs (e.g., Borsuk et al., 2001; Boyd and Wainger, 2002; Wainger et al., 2010; Goldstein et al., 2012; Bateman et al., 2013; Zheng et al., 2013; Johnston et al., 2016b). The development of adaptable, transferable models acceptable to decision makers that connect management-driven changes in ecosystems to changes in ecosystem service BRIs can help promote broader applications of this type of comprehensive work. Where sufficient need exists, generalized models of particular management actions or particular ecosystem services have been developed such as the FIRECLIM model for managing wildfire risk at the wildland urban interface (Paveglio and Prato, 2012; Olander et al., 2016). There are also numerous biophysical models that translate actions to biophysical changes such as changes in water quality (e.g., SWAT; Neitsch et al., 2011) or carbon sequestration (e.g., EPIC; Izaurralde et al., 2006). Such models typically do not attempt to translate biophysical endpoints to BRIs (work is still required to translate model outputs into BRIs), but models such as these are still important steps connecting actions to outcomes. Some general ecosystem service models exist such as the ARIES model (Villa et al., 2014) and the InVEST model (Sharp et al., 2015). Studies using InVEST have shown how changes in policy or management actions can be translate into BRIs (e.g., Nelson et al., 2009; Polasky et al., 2011; Goldstein et al., 2012; Bateman et al., 2013; Zheng et al., 2013). Researchers can also participate in the development of new predictive models that help to fill the gaps in estimating changes in ecosystem services.

A second gap that can occur once effects on BRIs are evaluated relates to the estimation of social values associated with changes in BRIs, whether through monetization or through non-monetary measures such as utility. Information on well-defined BRIs can still lead to misinformed decisions if those BRIs are linked to biased, incomplete or otherwise misleading measures of social value. Challenges in this area can relate to the difficulty of implementing valid, defensible and comprehensive valuation for some types of ecosystem services and the resources (e.g., time, money, expertise) required to do so (Bockstael et al., 2000). Researchers and decisionmakers often lack the capacity to implement high-quality ecosys- 
tem service valuation studies, leading to estimates of unclear validity, reliability and interpretation (Johnston et al., 2014). Moreover, there can be limited acceptance and understanding of established valuation methods by some decision-makers (NOAA SAB, 2016). In contexts such as this, there can be a temptation for researchers to rely on alternative measures of ecosystem service value with little or no grounding in established concepts or methods of economic valuation (Bockstael et al., 2000). The resulting measures cannot be meaningfully compared to well-defined economic measures of benefit or cost, and can lead to perverse decisions that reduce rather than enhance social welfare (Bockstael et al., 2000; Holland et al., 2010). Valuing these benefits accurately depends on the application of valid and defensible approaches.

Although the estimation of precise, site-specific measures of value often requires the application of resource-intensive primary valuation studies, cost-effective approximations of the can frequently be obtained via benefit transfer (Johnston and Wainger, 2015). The applicability of benefit transfer depends on the degree of precision (e.g., in estimated values) required in any particular context (Kline and Mazzotta, 2012). It also depends on the availability of prior studies that have estimated similar types of values in similar contexts-and that hence provide suitable information for transfer (Johnston and Wainger, 2015). The availability of these studies varies across regions and types of services. As discussed above within the context of ecological research, most of the valuation literature is characterized by site-specific research conducted for methodological purposes, divorced from the immediate needs of practitioners (Loomis and Rosenberger, 2006). A few types of ecosystem services have been subject to a sufficient number of primary valuation studies to enable meta-analyses or other types of data synthesis necessary to understand (and in some cases, predict) general patterns in value (Nelson and Kennedy, 2009; Johnston and Rosenberger, 2010). However, "the field of primary valuation studies is sparse in many areas, requiring tradeoffs between the quality and commensurability of studies [that may be considered in a data synthesis] and the number of studies available for analysis" (Rolfe et al., 2015, p. 362, chap. 16). Moreover, the tendency of economic journals to favor methodological advances over empirical contributions (and particularly replications) has led to "a lack of studies providing high quality, policy relevant, replicable, empirical estimates of non-market values for many environmental commodities" (Johnston and Rosenberger, 2010 , p. 496). The paucity of high quality valuation estimates is particularly severe for services that are not iconic or high profile (Rosenberger and Johnston, 2009). Because of the lower cost and effort involved in benefit transfer, wide spread improvements in valuation targeted to decision-maker needs is dependent on the provision of high quality empirical estimates of ecosystem service value suitable for benefit transfer (Johnston et al., 2015b).

\section{Strategy 2: Use methods that balance quality and feasibility}

Causal chains can be used to show conceptually how management actions lead to changes in ecological condition and to changes in ecosystem services that people value (Fig. 1). These causal chains are the foundation for the quantification of BRIs and associated values, and provide transparency about what steps are necessary. Yet all quantification is not equal. When quantifying changes in BRIs and values to support decisions, researchers must consider the dual goals of quality (i.e., using the best available biophysical and social science to represent the series of cause and effect relationships from management action to benefits) and feasibility (i.e., ensuring that models and tools are not too costly, complex and/or idiosyncratic for practical use by decision-makers) (Wainger and Mazzotta, 2011). While there is a need for more high-quality predictive models to fill gaps in connecting ecosystem management to changes in ecosystem services, many models developed by researchers are not used by practitioners due to factors such as complexity, site-specificity, data requirements, or cost (Johnston and Rosenberger, 2010). Decision makers require costeffective, straightforward, transferable, scalable, meaningful, and defensible methods that can be readily understood. Hence, the relevance of methods and models to quantify BRIs depends on the extent to which they (a) are of sufficient precision, scope and generalizability to provide the information required by decisionmakers, and (b) can be feasibly applied by decision-makers, considering factors such as cost, time and expertise.

The examples below are designed to illustrate tradeoffs that influence the relevance of alternative models and methods that might be used to integrate ecosystem services into decision making. The first example shows a case in which a simpler model (with less accurate data) provided sufficient information to move decisions forward with an acceptable level of confidence, cost, speed, and effort (Oregon wetlands). In this case, quality versus feasibility tradeoffs favored the use of a simple and feasible model. The second example illustrates a contrasting case in which a simpler model did not provide sufficient reliability, such that a more complex model was required to support decisions (California fire). These contrasting examples suggest that there is no "one size fits all" approach to the quality versus feasibility tradeoff, but that researchers who focus solely on the best available science (regardless of practicality or feasibility for decision-maker application) may miss opportunities for relevance.

\subsection{Methods example 1: Oregon state wetlands prioritization}

To illustrate considerations in the choice of ecosystem service quantification methods, we return to the example of wetland conservation, mitigation and restoration in Oregon (Oregon Wetland Rapid Assessment Protocol, ORWAP, Adamus et al., 2010). A challenge to implementing mitigation based on ecosystem services in this case is that wetland regulators in Oregon face a system that is difficult to change due to existing agreements with federal agencies. New methods or data can only be used if acceptable to all agencies and if agreements are renegotiated. Such agreement usually requires all agencies to co-develop tools or use an external peer review of a proposed tool, as a way of assuring credibility. Further, the use or development of tools that threaten to slow down the permitting process (e.g., due to their complexity or time required for approvals) may not be acceptable to stakeholders.

To provide an approach that was usable by regulators in this context, simple models were used to prioritize wetlands based on the following wetland benefits: property damage protection (due to flood risk reduction), late season water provision and temperature control, and support for recreational activities or species conservation via provisioning of habitat, food, water, and refugia (Adamus et al., 2010). For example, property damage avoided was modeled using simple functional relationships. Wetlands were compared based on their potential to reduce property losses, inferred from the combination of a basic biophysical functional metric of water holding capacity (Gleason et al., 2008) and the area of developed land downstream of the wetland that has the potential to be flooded. Accounting for the area of downstream developed land is necessary to interpret the model output as a BRI, because the water holding capacity of a wetland alone (a biophysical function) does not convey its relative contribution to property protection (the outcome that people value). A similar simplified model was used to forecast the influence of wetland changes on downstream drinking water or estuaries, realized via wetlands' capacity to remove phosphorus. The model combined information on phosphorus loads upstream from each wetland with wetland 
attributes corresponding to each wetland's capacity to remove phosphorus from water.

An additional constraint to developing these models was that state regulations require use of data from the National Wetlands Inventory (NWI) and the National Hydrologic Dataset (NHD), even though other data might be more appropriate (and accurate) for modeling ecosystem services. The team dealt with this challenge in two ways. To overcome limitations of the NWI, the team used supplemental spatial information to model wetlands services, but clearly traced the results back to the NWI classification system. In the case of the NHD, the team used data that they knew to be of variable quality across the state. Although using less accurate, but mandatory, data sources degraded model reliability to some extent, using more precise data would have rendered the method unusable by regulators. This tradeoff exemplifies the quality versus feasibility tradeoff that can occur when using models to support decision-making. Overlooking this tradeoff can lead to the development of models that are more accurate, but are nonetheless useless to decision-makers.

The relatively simple models proposed for use in Oregon have several aspects that promote their feasibility for the specific decision context. First, the methods are consistent with regulation and are relatively easy to understand, thereby supporting the need to achieve consensus among stakeholders. Second, the methods are quick to implement (once the GIS database has been developed), promoting an efficient permitting process. Further, if the final prioritization scheme were made public, state agencies and developers who impact wetlands would know in advance which wetlands are given the highest priority and could use that information during project design stages to avoid permitting problems.

Although a simplified approach was well suited to the decision context described above, a highly litigious permitting process could suggest the need for a more complex and defensible model. Because the proposed ecosystem service estimates depend on generalized relationships between site and landscape characteristics and wetland functional outputs and outcomes, the science could easily be disputed in court. Yet, given that field-based measurements or more precise models of how individual wetlands contribute to flood risk or phosphorus removal would need to be implemented individually for each of the over a million wetlands in Oregon, or even the thousands of wetlands in a given watershed, they are cost-prohibitive for regulatory use (Kentula, 2007).

Although simplicity (and perhaps the use of data known to be less accurate or otherwise inferior) may be required in many circumstances, simple models must still be tested in terms of whether they are "good enough" to meet practitioner's goals and balance tradeoffs, both from an ecological production and ecosystem service value standpoint. Researchers can help in this regard by testing ecological production functions and effects of data limitations on the model. In the present case, one test has already been conducted that suggested that using locally-derived data that were more accurate than readily available national data did not substantially affect wetland prioritizations (Chang, 2007). In addition to testing by technical experts, a model being used for policy can be vetted through a collaborative process with all stakeholders, including all regulated entities. Such vetting would evaluate whether any assumptions, aggregation methods, or missing variables were biasing results or generating unintended consequences.

\subsection{Methods example 2: Reducing fire risk along utility lines in California}

In October 2007, dozens of wildfires, fueled by strong Santa Ana winds, burned through Southern California. The fires burned 780 square miles, killed 17 people, and destroyed thousands of homes and buildings. Several of the worst wildfires were reportedly ignited by overhead power lines and aerial communications facilities in close proximity to power lines. In response to the widespread devastation, the California Public Utility Commission issued an order to consider and adopt regulations to reduce such risks. At the time there were three interim fire-threat maps for use with fire prevention measures such as vegetation management. Two of these maps were specifically designed to identify areas with heightened risk of power-line fires; however, they had not been peer- reviewed, did not contain sufficient spatial resolution, and did not cover the entire state in a consistent fashion. The third map that did cover the entire state was determined by fire managers to be ill-suited to identify high-risk areas for power-line fires, but it was adopted because there was no better statewide fire-threat map available. As a result, the Utilities Commission concluded that the third map should be replaced with a statewide purpose-built fire-threat map. This map would be reviewed by neutral resource experts before it was permanently adopted. The Commission defined the general criteria of a high reliability map that captures the ecological complexity of wildfires to help solve their fire management problem. This new utility fire risk map was to be combined with local knowledge on property and infrastructure to inform the development of modified regulations on utility vegetation management, with the intention of reducing the risk to assets (Fig. 5).

In response to the Commission's request, researchers developed a comprehensive index designed to describe the magnitude of utility fire threat. This index was designed to incorporate the fundamental physical and environmental features that increase

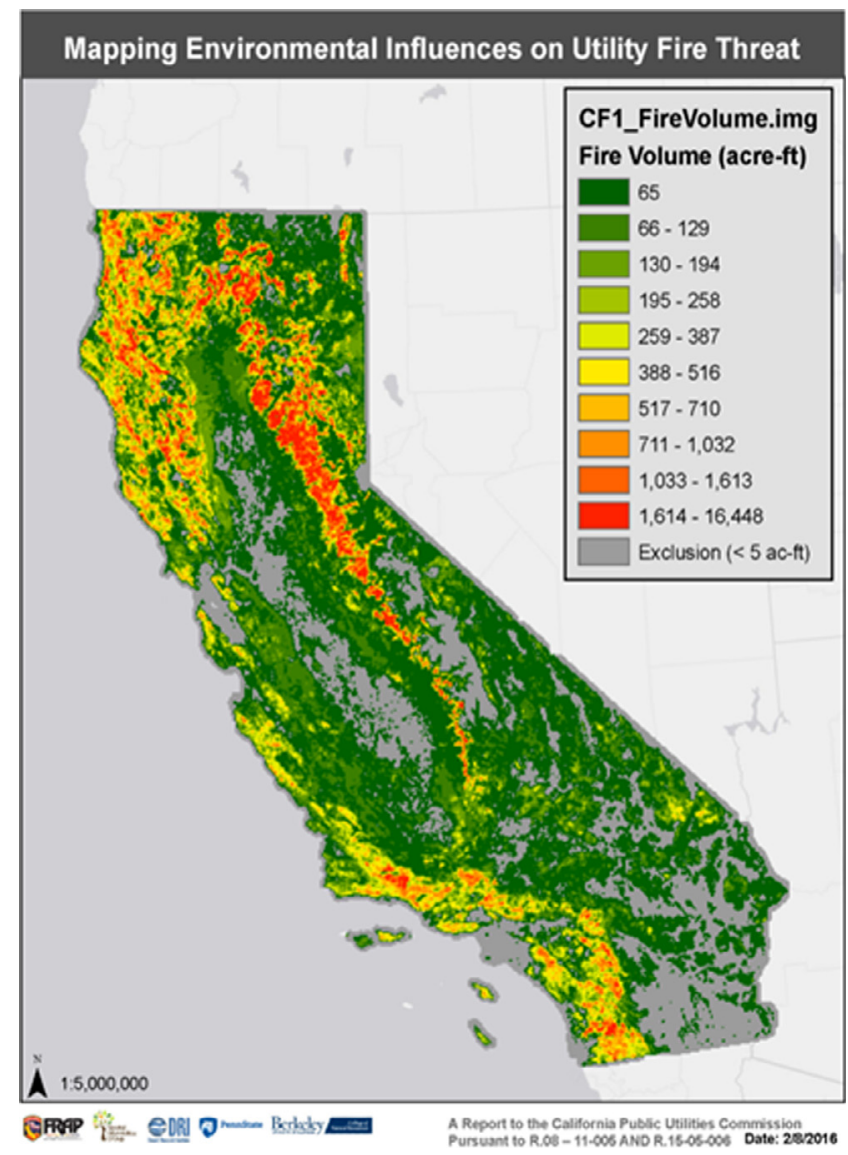

Fig. 5. A utility fire threat map showing a unit less index of the probability of an extreme event occurring. The model used to generate the map integrates climate projections and vegetation variables to simulate a thousand wildfire scenarios to estimate the probability of extreme wildfire weather conditions. 
the likelihood that overhead utility facilities will initiate large wildfires that pose a significant treat to people and property. The first step consisted of the construction of a ten-year comprehensive climate reconstruction of key fire weather variables for the entire state of California. Using this data and other information describing the fire environment, the teams created two main subcomponents: 1) an Ignition Potential Index that indicates an area's likelihood for producing an ignition point; and 2) a Fire Spread Index that evaluates the subsequent potential of the ignition to result in a large fire. A Monte Carlo model was then used to determine the probability of high threat fires. A final Utility Fire Threat Index map was created as the product of the ignition potential and spread potential (Fig. 5).

Although relevance requires that researchers consider the quality versus feasibility tradeoff, it does not necessarily dictate the use of simplified, less accurate modeling. This example illustrates a case in which simplified methods were available, but were judged to be of insufficient quality (i.e., ability to accurately predict fire risk) to meet decision-makers' needs. That is, unlike the Oregon wetlands case study above, here quality versus feasibility tradeoffs led decision-makers to demand more complex and accurate models. In the present case, the final, more complex model had four significant advantages over the previous more simplified methods: it was repeatable, it was consistent, it assessed uncertainty, and it integrated the most current understanding of fire science into one map data product.

\subsection{Challenges and opportunities in balancing model quality versus feasibility}

High-quality primary research that fully reflects system complexity is often assumed to be more reliable (repeatable and accurate), but is often infeasible given resource constraints and over the scales required to inform decision-making. On the other hand, ecosystem services research conducted using some off-the-shelf tools can lead to substantial errors in forecasting (Johnston and Wainger, 2015). The accuracy of research methods must be matched to the needs of particular decision contexts (Kline and Mazzotta, 2012). The resulting challenges for the research community are to (1) deliver feasible ecosystem service research tools and data that meet practitioner needs and (2) help practitioners make informed decisions about quality versus feasibility tradeoffs-for example decisions that reflect the information and accuracy sacrificed when using simplified methods. Related questions for ecosystem service researchers include: (1) to what degree is reliability sacrificed as one moves to simpler and more feasible methods, (2) can new methods and data be developed to improve reliability in a cost-effective manner, and (3) what type of simplified approaches are sufficient for different types of decision-making?

A stylized feasibility versus reliability frontier is illustrated in Fig. 6. The upward sloping line shows the maximum reliability possible for a given cost and effort. As illustrated here, increasing reliability requires costs and effort to increase at an increasing rate. This is shown for illustration purposes only-actual feasibility versus reliability frontiers may take on many different shapes and functional forms. Beyond the anticipated positive relationship between reliability and required cost and effort, among the primary observations from this graph is that the need for reliability in ecosystem service quantification and valuation depends on the decision context. Certain types of decisions (e.g., damage assessments for litigation) require very high reliability, and hence high costs and effort. Others, such as initial feasibility assessments or preliminary project scoping, require lower reliability.

As noted above, researchers who target their work at a much higher or lower point on the research reliability frontier than is appropriate for a given decision context risk reducing (or eliminat-



Fig. 6. Tradeoffs between increased reliability of results and the cost and effort required.

ing) the relevance of their work. Yet what is the correct point? And what is the shape of this frontier? The specific values along the reliability-cost frontier, and the shape of the curve, are almost always unknown. The benefits of additional modeling effort and complexity (e.g., requiring more data collection and more intensive modeling) in terms of increased reliability in ecosystem service results have been subject to conjecture but little systematic analysis. Information directly or indirectly relevant to these questions is scattered across multiple areas of the literature (e.g., Allen and Loomis, 2008; Bateman et al., 2011; Merow et al., 2014; Rosenberger, 2015, chap. 14), but this information is insufficient at present to characterize general feasibility versus reliability tradeoffs.

Confounding the challenge of identifying tradeoffs between reliability and feasibility is the potentially high variability of modeling outcomes, due partly to variable exogenous factors (e.g., weather or stochastic population dynamics) and to non-linear system dynamics. Non-linear responses can occur either in biophysical relationships (e.g., a small increase in nutrients triggers a large self-sustaining increase in algae) or in the value generated from ecosystem services (e.g., small increases that reduce water quality below mandated standards). Where thresholds such as these occur, small modeling errors can lead to large implications for policy or management decisions, increasing the risks that inaccurate models will lead to poor decisions. Determining how complex models need to be for different levels of reliability (and policy relevance) is an important research frontier that can help to inform the practice and use of ecosystem service information in decision making.

Thus far, this discussion has been predicated on the existence of a single reliability frontier. However, over time, researchers can contribute to activities that shift this frontier, thereby making reliable ecosystem services models more cost-effective. Such activities can significantly enhance the potential long-term relevance of ecosystem services research. For example, the development of reliable and cost-effective models is often constrained by the availability of existing ecological, social and value data that can be used to develop models of any type (e.g., empirical, statistical, probabilistic, mechanistic), or to calibrate and validate such models (Naidoo et al., 2008). Enhancing data availability can therefore enhance the cost-effectiveness of ecosystem services research. Researchers can help by supporting the development of systematic data collection in their research and the public use of their data in developing data libraries. Researchers can also help to inform the development of improved monitoring programs or new data 
libraries and identify what data should be collected and how these data should be made available.

Underlying raw data rather than integrated scores are often most useful. For example, integrated, classified attributes such as an overall rapid wetland assessment protocol score commonly used in wetland mitigation programs has limited utility in developing models that can evaluate multiple ecosystem service outputs. However, the underlying data gathered while developing the score includes relevant information on hydrology, wildlife and vegetation that can inform ecosystem service outputs (Gleason et al., 2008). In cases such as these, access to the raw data may be more useful to ecosystem services research than the initial modeling results. Another example is land cover. Many of the ecosystem service analyses rely heavily on classified land cover maps. These maps are extremely useful as broad scale characterizations, but the classifications merge and sometimes hide a vast array of relatively high resolution spatial prediction data. Having the imagery, geographic attributes and the base monitoring training data used to create these land cover datasets, combined with new remote sensing improvements now available could significantly improve the information available for linking services to beneficiaries (Ohmann and Gregory, 2002).

Collection of valuation data is also critical. For example, recent work in the economics literature discusses study design and reporting needs for economic valuation to enable synthesis and policy application (Johnston et al., 2015b; Loomis and Rosenberger, 2006). Valuation databases and data syntheses make this work increasingly accessible to policymakers (McComb et al., 2006; Johnston and Thomassin, 2009; Santos et al., 2012). However, extant databases only include a small fraction of the literature on ES valuation, and most published work fails to provide even basic information (e.g., spatial information; Johnston et al., 2016a) required for reliable policy analysis.

In these and other cases, improved access to well-documented biophysical and social data can enable ecosystem services researchers to conduct research that is simultaneously less costly and more reliable, shifting the research reliability frontier (Fig. 6) down and to the right. Over time, this can help facilitate the use of more accurate research results to inform decisions, because research can be at once more feasible and reliable.

\section{Conclusions}

The growing awareness of nature's social benefits has led to increased demand by decision-makers for decision relevant ecosystem service research. While there has been a concurrent increase in the supply of ecosystem service research published in academic journals and similar outlets, there is a lack of relevant research that practitioners can use to inform decision making in many contexts (Polasky et al., 2015). There is a pressing need for policy and management relevant research on ecosystem services to correct this mismatch between demand and supply. The goal of this paper is to identify some of the primary reasons for this mismatch, and provide suggestions that researchers can use to help enhance the short- and long-run relevance of ecosystem services research.

Many of the necessary pieces for producing research relevant for decisions that affect ecosystem services already exist. There is a growing body of scientific research from the natural sciences on how ecosystems function. There is also a large and expanding literature from economics and other social sciences on values people derive from nature. However, at present there are few examples of high quality research that models the complete causal chain from policy or management action through effects on ecosystems all the way to benefits received by identifiable groups of people. Often the key missing link is at the interface between ecosystem functions and measures of natural outputs that people value-or BRIs. Identifying and modeling BRIs requires the coordination of both social science and biophysical research, and is one of the most effective ways to increase the relevance of ecosystem services research.

Yet even when BRIs can be quantified and linked to actions, the applied models must be appropriate to the capacity and needs of decision-makers. Ensuring that models are useful requires engagement between researchers and decision-makers. Active and ongoing dialog among researchers, practitioners, and decisionmakers is essential to enhancing the relevance of ecosystem services research (Ruckelshaus et al., 2015; Posner et al., 2016). Improving researchers' understanding of the decisions practitioners are making, the time and resource limitations they face, legal and regulatory constraints, constraints on data acquisition and analysis, and the form in which practitioners need to receive information, can help guide the design of a policy-relevant research program. The long-term relevance of ecosystem services research can also be enhanced by the development of accessible data repositories that can be used by researchers to develop models that are both sufficiently cost-effective and reliable for application to policy and management decisions.

Such efforts may seem "too applied" and not enough on the frontiers of disciplinary-based science to excite some researchers. But we think that this type of work offers its own challenges and rewards. It is challenging to synthesize knowledge from across different disciplines, created with differing assumptions and objectives, into a useful integrated causal chain. However, success in such integration is increasingly recognized and rewarded by journals, departments, institutions and funding agencies that value innovative and relevant work.

It is also challenging to work within the constraints of existing data and institutions to come up with good, though necessarily imperfect, analyses that can inform decision-making. Hence, successful advances that facilitate the provision of relevant and usable ecosystem services information can be rewarding both in terms of the traditional metrics of academics (publications, citations and grants) and benefits to society from better policy and management decisions.

\section{Acknowledgements}

This work was supported by the National Socio-Environmental Synthesis Center (SESYNC) with funding received from the National Science Foundation DBI-1052875 and the David and Lucille Packard Foundation in support of the National Ecosystem Services Partnership.

We appreciate the assistance of Nichole Basenback on one of the figures and would like to thank two anonymous reviewers for their helpful advice.

\section{References}

Abt Associates. 2015. Developing Socio-Economic metrics to measure DOI Hurricane Sandy Project and Program Outcomes. Prepared for NFWF. https:// www.doi.gov/sites/doi.gov/files/uploads/Socio_Economic_Metrics_Final_ Report_11DEC2015_0.pdf.

Adamus, P., Morlan, J., Verble, K., 2010. Manual for the Oregon Rapid Wetland Assessment Protocol (ORWAP). Version 2.0.2. Oregon Department of State Lands, Salem, OR.

Ager, A., Finney, M., McMahan, A., Cathcart, J., 2010. Measuring the effect of fuel treatments on forest carbon using landscape risk analysis. Nat. Hazards Earth Syst. Sci. 10, 2515-2526.

Allen, B.P., Loomis, J.B., 2008. The decision to use benefit transfer or conduct original valuation research for benefit-cost and policy analysis. Contemp. Econ. Policy 26, 1-12. 
Barbier, E.B., Hacker, S.D., Kennedy, C., Koch, E., Stier, A.C., Silliman, B.R., 2011. The value of estuarine and coastal ecosystem services. Ecol. Monogr. 81, 169193.

Bateman, Ian J., Carson, Richard T., Day, Brett H., Michael Hanemann, W., Hanley, Nick, Hett, Tanis, Jones-Lee, Michael, Loomes, Graham, Mourato, Susana, Özdemiroglu, Ece, Pearce, David W., 2002. Economic Valuation with Stated Preference Techniques: A Manual. Edward Elgar, Cheltenham, UK.

Bateman, I.J., Brouwer, R., Ferrini, S., Schaafsma, M., Barton, D.N., Dubgaard, A. Hasler, B., Hime, S., Liekens, I., Navrud, S., De Nocker, L., Ščeponavičiūtè, R., Semènienè, D., 2011. Making benefit transfers work: deriving and testing principles for value transfers for similar and dissimilar sites using a case study of the non-market benefits of water quality improvements across Europe. Environ. Resource Econ. 50, 365-387.

Bateman, I.J., Harwood, A.R., Mace, G.M., Watson, R.T., Abson, D.J., Andrews, B. Binner, A., Crowe, A., Day, B.H., Dugdale, S., Fezzi, C., Foden, J., Hadley, D. Haines-Young, R., Hulme, M., Kontoleon, A., Lovett, A.A., Munday, P., Pascual, U., Paterson, J., Perino, G., Sen, A., Siriwardena, G., van Soest, D., Termansen, M. 2013. Bringing ecosystem services into economic decision-making: land use in the United Kingdom. Science 341, 45-50.

Bauer, D.M., Johnston, R.J., 2013. The economics of rural and agricultural ecosystem services: purism versus practicality. Agric. Resour. Econ. Rev. 42 (1), iii-Xv.

Benda, L., Miller, D., Barquin, J., McCleary, R., Cai, T.J., Ji, Y., 2016. Building virtua watersheds: a global opportunity to strengthen resource management and conservation. Environ. Manage. 57 (3), 722-739.

Blamey, R.K., Bennett, J.W., Louviere, J.J., Morrison, M.D., Rolfe, J.C., 2002. Attribute causality in environmental choice modeling. Environ. Resource Econ. 23, 167 186.

Bockstael, N.E., Freeman, A.M., Kopp, R.J., Portney, P.R., Smith, V.K., 2000. On measuring economic values for nature. Environ. Sci. Technol. 34 (8), 13841389.

Borsuk, M., Clemen, R., Maguire, L., Reckhow, K., 2001. Stakeholder values and scientific modeling in the Neuse river watershed. Group Decis. Negot. 10, 355 373.

Boyd, J., Wainger, L., 2002. Landscape indicators of ecosystem service benefits. Am. J. Agric. Econ. 84, 1371-1378.

Boyd, J., Krupnick, A., 2013. Using ecological production theory to define and select environmental commodities for nonmarket valuation. Agric. Resour. Econ. Rev. 42 (1), 1-32.

Boyd, J., Ringold, P., Krupnick, A., Johnston, R.J., Weber, M.A., Hall, K., 2016 Ecosystem services indicators: improving the linkage between biophysical and economic analyses. Int. Rev. Environ. Resour. Econ. 8, 359-443.

Braat, L.C. (ed.) (2015) Mapping of Ecosystems and their Services in the EU And its Member States (MESEU) SYNTHESIS REPORT 2012-2015. CONTRACT: ENV.B.2 SER/2012/0016. European Commission, Brussels.

Carpenter, S.R., Mooney, H.A., Agard, J., Capistrano, D., DeFries, R.S., Díaz, S., Dietz, T. Duraiappah, A.K., Oteng-Yeboah, A., Pereira, H.M., Perrings, C., Reid, W.V. Sarukhan, J., Scholes, R.J., Whyte, A., 2009. Science for managing ecosystem services: beyond the millennium ecosystem assessment. PNAS 106 (5), 13051312. http://dx.doi.org/10.1073/pnas.0808772106, published ahead of print January 28, 2009.

Chang, H., 2007. Comparative streamflow characteristics in urbanizing basins in the Portland Metropolitan Area, Oregon, USA. Hydrol. Process. 21, 211-222.

Executive Office of the President of the United States 2015. Memorandum for Executive Departments and Agencies on "Incorporating Ecosystem Services into Federal Decision Making. https://www.whitehouse.gov/sites/default/files/omb/ memoranda/2016/m-16-01.pdf.

Gleason RA, Laubhan MK, Euliss NH Jr (eds). 2008. Ecosystem services derived from wetland conservation practices in the United States prairie pothole region with an emphasis on the United States Department of Agriculture Conservation Reserve and Wetlands Reserve programs. United States Geological Survey Northern Prairie Wildlife Research Center paper 110.

Goldstein, J.G., Caldarone, T.K., Duarte, D., Ennaanay, N., Hannahs, G., Mendoza, S., Polasky, S..Wolny., Daily, G.C., 2012. Integrating ecosystem service tradeoffs into land-use decisions. Proc. Natl. Acad. Sci. 109 (19), 7565-7570.

Goodkind, A.L., Polasky, S., Taff, S.J., 2013. Ecosystem Service Damages from Proposed NorthMet Mine. Department of Applied Economics, University of Minnesota, St. Paul, MN.

Google Scholar Search. July 18, 2016. (No patents or case law included in search).

Griffiths, C., Wheeler, W., 2005. Benefit-cost analysis of regulations affecting surface water quality in the United States. In: Brouwer, R., Pearce, D. (Eds.), Cost-Benefit Analysis and Water Resources Management. Edward Elgar, Cheltenham, UK, pp. 223-250.

Guerry, A., Polasky, S., Lubchenco, J., Chaplin-Kramer, R., Daily, G.C., Griffin, R. Ruckelshaus, M.H., Bateman, I.J., Duraiappah, A., Elmqvist, T., Feldman, M.W., Folke, C., Hoekstra, J., Kareiva, P., Keeler, B., Li, S., McKenzie, E., Ouyang, Z. Reyers, B., Ricketts, T., Rockström, J., Tallis, H., Vira, B., 2015. Natural capita informing decisions: from promise to practice. Proc. Natl. Acad. Sci. 112, 7348 7355.

Halofsky, J.E., M.K. Creutzburg, and M.A. Hemstrom. 2014. Integrating Social, Economic, and Ecological Values Across Large Landscapes. USDA Forest Service, General Technical Report (PNW-GTR-896), PNW Research Station, Portland, OR 216 pp. https://www.fs.fed.us/pnw/pubs/pnw gtr896.pdf.

Hanley, N., Hynes, S., Patterson, D., Jobstvogt, N., 2015. Economic valuation of marine and coastal ecosystems: is it currently fit for purpose? J. Ocean Coastal Econ. 2: Article 1.
Holland, D.S., Sanchirico, J., Johnston, R.J., Joglekar, D., 2010. Economic Analysis for Ecosystem Based Management: Applications to Marine and Coastal Environments. RFF Press, Washington, DC.

Holmes, T.P., Bergstrom, J.C., Huszar, E., Kask, S.B., Orr III, F., 2004. Contingent valuation, net marginal benefits, and the scale of riparian ecosystem restoration. Ecol. Econ. 49 (2), 19-30.

Hurteau, M.D., Hungate, B.A., Koch, G.W., 2009. Accounting for risk in valuing forest carbon offsets. Carbon Balance Manage. 4, 14.

“IPBES | Intergovernmental Platform On Biodiversity And Ecosystem Services". Ipbes.net. N.p., 2016. Web. 18 July 2016.

Izaurralde, R.C., Williams, J.R., McGill, W.B., Rosenberg, N.J., Jakas, M.C.Q., 2006. Simulating soil C dynamics with EPIC: Model description and testing against long-term data. Ecol. Model. 192, 362-384.

Johnston, R.J., Thomassin, P.J., 2009. Evaluating the environmental valuation reference inventory (EVRI): results from a survey of actual and potential users. Assoc. Environ. Res. Econ. Newslett. 29 (1), 33-38.

Johnston, R.J., Rosenberger, R.S., 2010. Methods, trends and controversies in contemporary benefit transfer. J. Econ. Surv. 24, 479-510.

Johnston, R.J., Schultz, E.T., Segerson, K., Besedin, E.Y., Ramachandran, M., 2012. Enhancing the content validity of stated preference valuation: the structure and function of ecological indicators. Land Econ. 88 (1), 102-120.

Johnston, R.J., Schultz, E.T., Segerson, K., Besedin, E.Y., Ramachandran, M., 2013. Stated preferences for intermediate versus final ecosystem services: Disentangling willingness to pay for omitted ecological outcomes. Agric. Res. Econ. Rev. 42 (1), 98-118.

Johnston, R.J., Swallow, S.K., Bauer, D.M., Uchida, E., Anderson, C.M., 2014 Connecting ecosystem services to land use: implications for valuation and policy. In: Duke, J.M., Wu, J. (Eds.), The Oxford Handbook of Land Economics. Oxford University Press, pp. 196-225. chapter 8.

Johnston, R.J., Rosenberger, R.S., Rolfe, J., Brouwer, R., 2015. Benefit transfer: the present state and future prospects. In: Johnston, R.J., Rolfe, J., Rosenberger, R.S., Brouwer, R. (Eds.), Benefit Transfer of Environmental and Resource Values: A Guide for Researchers and Practitioners. Springer, Dordrecht, the Netherlands. Chapter 24.

Johnston, R.J., Wainger, L.A., 2015. Benefit transfer for ecosystem service valuation: An introduction to theory and methods. In: Johnston, R.J., Rolfe, J., Rosenberger, R.S., Brouwer, R. (Eds.), Benefit Transfer of Environmental and Resource Values: A Guide for Researchers and Practitioners. Springer, Dordrecht, the Netherlands. Chapter 12.

Johnston, R.J., E.Y. Besedin and R. Stapler. 2016a. Enhanced Geospatial Validity for Meta-Analysis and Environmental Benefit Transfer: An Application to Water Quality Improvements. Environmental and Resource Economics (Online First; print version in press)

Johnston, R.J., Schultz, E.T., Segerson, K., Besedin, E.Y., Ramachandran, M., 2016b. Biophysical causality and environmental preference elicitation: evaluating the validity of welfare analysis over intermediate outcomes. Am. J. Agric. Econ. http://dx.doi.org/10.1093/ajae/aaw073; print version in press). Advance Access online, print version in press.

Johnston, R.J., K.J. Boyle, W. Adamowicz, J. Bennett, R. Brouwer, T.A. Cameron, W.M Hanemann, N. Hanley, M. Ryan, R. Scarpa, R. Tourangeau and C.A. Vossler. 2017. Contemporary Guidance for Stated Preference Studies. Journal of the Association of Environmental and Resource Economists (in press).

Kentula, M.E., 2007. Forward: Monitoring wetlands at the watershed scale. Weltands 27 (3), 412-415.

Keeler, B., Polasky, S., Brauman, K.A., Johnson, K.A., Finlay, J.C., O’Neill, A., Kovacs, K. Dalzell, B., 2012. Linking water quality and well-being for improved assessment and valuation of ecosystem services. Proc. Natl. Acad. Sci. 109, 18619-18624.

Kline, J.D. and M.J. Mazzotta. 2012. Evaluation of Trade-offs among Ecosystem Services in the Management of Public Lands. U.S. Department of Agriculture, Forest Service, Pacific Northwest Research Station, General Technical Report PNW-GTR-865. http://www.fs.fed.us/pnw/pubs/pnw gtr865.pdf.

Larruca, E.S., Brussard, B.F., 2008. Habitat selection and current distribution of the Pygmy Rabbit in Nevada and California. J. Mammol. 89, 691-699.

Lawler, J.J., Lewis, D.J., Nelson, E., Plantinga, A.J., Polasky, S., Withey, J.C., Helmers, D. P., Martinuzzi, S., Pennington, D., Radeloff, V.C., 2014. Projected land-use change impacts on ecosystem services in the U.S. Proc. Natl. Acad. Sci. 111 (20), 74927497.

Lipton, D., Lew, D., Wallmo, K., Wiley, P., Dvarskas, A., 2014. The evolution of nonmarket valuation of U.S. coastal and marine resources. J. Ocean Coastal Econ. 2014

Loiselle, B.A., Howell, C.A., Graham, C.H., Goerck, J.M., Brooks, T., Smith, K.G. Williams, P.H., 2003. Avoiding pitfalls of using species distribution models in conservation planning. Conserv. Biol. 17, 1591-1600.

Loomis, J.B., Rosenberger, R.S., 2006. Reducing barriers in future benefit transfers: Needed improvements in primary study design and reporting. Ecol. Econ. 60, 343-350.

McComb, G., Lantz, V., Nash, K., Rittmaster, R., 2006. International valuation databases: overview, methods and operational issues. Ecol. Econ. 60, 461-472.

Merow, C. Smith, MJ., Edwards, T.C., Guisan, A., McMahon, S.M., Normand, S., Thuiller, W., Wüest, R.O., Zimmermann, N.E., Elith, J., 2014. What do we gain from simplicity versus complexity in species distribution models? Ecography 37, 1267-1281.

Miller, J., Safford, H., Crimmins, M., Thode, A., 2009. Quantitative evidence for increasing forest fire severity in the Sierra Nevada and southern Cascade Mountains, California and Nevada, USA. Ecosystems 12, 16-32. 
Naidoo, R., Balmford, A., Costanza, R., Fisher, B., Green, R.E., Lehner, B., Malcolm, T.R., Ricketts, T.H., 2008. Global mapping of ecosystem services and conservation priorities. Proc. Natl. Acad. Sci. 105 (28), 9495-9500.

National Ecosystem Services Partnership (NESP), 2016. Federal Resource Management and Ecosystem Services Guidebook. National Ecosystem Services Partnership, Duke University, Durham. https://nespguidebook.com.

National Oceanic and Atmospheric Administration Science Advisory Board (NOAA SAB). 2016. An Assessment of the Use and Potential Use of Ecosystem Service Valuation (ESV) within NOAA A Report from the NOAA Science Advisory Board. Silver Spring, Maryland.

The Declaration | Natural Capital Declaration“. 2012. Naturalcapitaldeclaration.org. N.p., 2016. Web. 18 July 2016.

Neitsch, S.L., J.G. Arnold, J.R. Kiniry, and J.R. Williams. 2011. Soil and Water Assessment Tool Theoretical Documentation Version 2009. Texas Water Resources Institute.

Nelson, E., Mendoza, G., Regetz, J., Polasky, S., Tallis, H., Cameron, D.R., Chan, K.M.A. Daily, G., Goldstein, J., Kareiva, P., Lonsdorf, E., Naidoo, R., Ricketts, T.H., Shaw, M.R., 2009. Modeling multiple ecosystem services, biodiversity conservation, commodity production, and tradeoffs at landscape scales. Front. Ecol. Environ. 7 (1), 4-11.

Nelson, J.P., Kennedy, P.E., 2009. The use (and abuse) of meta-analysis in environmental and resource economics: an assessment. Environ. Resource Econ. 42, 345-377.

Ohmann, J.L., Gregory, M.J., 2002. Predictive mapping of forest composition and structure with direct gradient analysis and nearest- neighbor imputation in coastal Oregon, U.S.A. Can. J. For. Res. 32 (4), 725-741. http://dx.doi.org/ 10.1139/x02-011.

Olander, L., Johnston, R.J., Tallis, H., Kagan, J., Maguire, L., Polasky, S., Urban, D., Boyd, J., Wainger, L., Palmer, M., 2015. Best Practices for Integrating Ecosystem Services into Federal Decision Making. National Ecosystem Services Partnership, Duke University, Durham. doi:10.13016/M2CH07.

Olander, L., Characklis, G.W., Comer, P., Effron, M., Gunn, J., Holmes, T., Johnston, R., Kagan, J., Lehman, W., Loomis, J., McPhearson, T., Neale, A., Patterson, L., Richardson, L., Ross, M., Saah, D., Sifleet, S., Stockmann, K., Urban, D., Wainger, L., Winthrop, R., Yoskowitz, D., 2016. Data and Modeling Infrastructure for National Integration of Ecosystem Services into Decision Making: Expert Summaries. National Ecosystem Services Partnership, Duke University, Durham.

Ouyang, Z., Zheng, H., Xiao, Y., Polasky, S., Liu, J., Xu, W., Wang, Q., Zhang, L., Xiao, Y., Rao, E., Jiang, L., Lu, F., Wang, X., Yang, G., Gong, S., Wu, B., Zeng, Y., Yang, W., Daily, G.C., 2016. Improvements in ecosystem services from investments in natural capital in China. Science 352, 1455-1459.

Paveglio, T.B., Prato, T., 2012. Integrating dynamic social systems into assessments of future wildfire losses: an experiential agent-based modeling approach. In: Dupont, H.C. (Ed.), Environmental Management: Systems, Sustainability and Current Issues. Nova Science Publishers Inc, Hauppauge, NY.

Polasky, S., Nelson, E., Pennington, D., Johnson, K., 2011. The impact of land-use change on ecosystem services, biodiversity and returns to landowners: a case study in the State of Minnesota. Environ. Resource Econ. 48 (2), 219-242.

Polasky, S., Tallis, H., Reyers, B., 2015. Setting the bar: standards for ecosystem services. Proc. Natl. Acad. Sci. 112, 7356-7361.

Posner, S. M., E. McKenzie, and T.H. Ricketts. 2016. Policy impacts of ecosystem services knowledge. PNAS 2016113 (7) 1760-1765.

President's Council of Advisors on Science and Technology, 2011. Report to the President: Sustaining Environmental Capital: Protecting Society and The Economy. Executive Office of the President. https://obamawhitehouse. archives.gov/sites/default/files/microsites/ostp/pcast_sustaining_environmental_capital_report.pdf

Reddy, S., McDonald, R.I., Maas, A.S., Rogers, A., Girvetz, E.H., North, J., Molnar, J., Finley, T., Leathers, G., Dimuro, J.L., 2015. Finding solutions to water scarcity: Incorporation ecosystem service values into business planning at The Dow Chemical Company's Freeport, TX facility. Ecosyst. Serv. 12, 94-107.

Ribaudo, M., Greene, C., Hansen, L., Hellerstein, D., 2010. Ecosystem services from agriculture: steps for expanding markets. Ecol. Econ. 69 (11), 2085-2092.
Rolfe, J., Brouwer, R., Johnston, R.J., 2015. Meta-analysis: Rationale, issues and applications. In: Johnston, R.J., Rolfe, J., Rosenberger, R.S., Brouwer, R. (Eds.) Benefit Transfer of Environmental and Resource Values: A Guide for Researchers and Practitioners. Springer, Dordrecht, the Netherlands.

Rosenberger, R.S. 2015. Benefit transfer validity and reliability. 2015. Chapter 14 in R.J. Johnston, J. Rolfe, R.S. Rosenberger and R. Brouwer, eds. Benefit Transfer of Environmental and Resource Values: A Guide for Researchers and Practitioners. Dordrecht, the Netherlands: Springer.

Rosenberger, R.S., Johnston, R.J., 2009. Selection effects in meta-analysis and benefit transfer: avoiding unintended consequences. Land Econ. 85 (3), 410-428.

Ruckelshaus, M., McKenzie, E., Tallis, H.M., Guerry, A.D., Daily, G.C., Kareiva, P.M., Polasky, S., Ricketts, T., Bhagabati, N., Wood, S., Bernhardt, J., 2015. Notes from the field: lessons learned from using ecosystem services to inform real-world decisions. Ecol. Econ. 115, 11-21.

Santos, C.P., Carollo, C., Yoskowitz, D.W., 2012. Gulf of Mexico Ecosystem Service Valuation Database (GecoServ): gathering ecosystem services valuation studies to promote their inclusion in the decision-making process. Mar. Policy 36, 214 217.

Schaefer, M., Goldman, E., Bartuska, A.M., Sutton-Grier, A., Lubchenco, J., 2015. Nature as capital: advancing and incorporating ecosystem services in United States federal policies and programs. Proc. Natl. Acad. Sci. 112, 7383-7389.

Schultz, E.T., Johnston, R.J., Segerson, K., Besedin, E.Y., 2012. Integrating ecology and economics for restoration: using ecological indicators in valuation of ecosystem services. Restor. Ecol. 20 (3), 304-310.

Sharp, R. et al. 2015. InVEST User's Guide. The Natural Capital Project, Stanford University, University of Minnesota, The Nature Conservancy, and World Wildlife Fund.

Syphard, A.D., Scheller, R.M., Ward, B.C., Spencer, W.D., Strittholt, J.R., 2011 Simulating landscape-scale effects of fuels treatments in the Sierra Nevada California, USA. Int. J. Wildland Fire 20 (3), 364-383. http://dx.doi.org/10.1071/ WF09125.

The Economics of Ecosystems and Biodiversity (TEEB), 2012. In: Bishop (Ed.), The Economics of Ecosystems and Biodiversity in Business and Enterprise. Earthscan, London and New York.

U.S. Environmental Protection Agency (US EPA). 2009. Valuing the Protection of Ecological Systems and Services. A Report of the EPA Science Advisory Board. EPA-SAB-09-012. Washington D.C.

Villa, F., Bagstad, K.J., Voigt, B., Johnson, G.W., Portela, R., Honzak, M., Batker, D. 2014. A methodology for adaptable and robust ecosystem services assessment. PLOS ONE 9 (3), 1-18.

Wainger, L., Mazzotta, M., 2011. Realizing the potential of ecosystem services: a framework for relating ecological changes to economic benefits. Environ. Manage. 48, 710-733.

Wainger, L.A., King, D.M., Mack, R.N., Price, E.W., Maslin, T., 2010. Can the concept of ecosystem services be practically applied to improve natural resource management decisions? Ecol. Econ. 69 (5), 978-987.

Wallmo, K., Lew, D.K., 2011. Valuing improvements to threatened and endangered marine species: An application of stated preference choice experiments. J. Environ. Manage. 9 (7), 1793-1801.

"WAVES| Wealth Accounting And The Valuation Of Ecosystem Services". Wavespartnership.org. N.p., 2016. Web. 18 July 2016.

Wildland Fire Leadership Council, 2011. National Cohesive Wildland Fire Management Strategy. https://www.doi.gov/wildlandfire/cohesive-strate

Wondzell, S.M. Hemstrom, M.A.,Bisson, P. A, 2007. Simulating riparian vegetation and aquatic habitat dynamics in response to natural and anthropogenic disturbance regimes in the Upper Grande Ronde River, Oregon, USA. Landsc Urban Plan. 80 (3), 249-267.

Wong, C.P., Jiang, B., Kinzig, A.P., Lee, K.N., Ouyang, Z., 2015. Linking ecosystem characteristics to final ecosystem services for public policy. Ecol. Lett. 18, 108118.

Zheng, $\mathrm{H}$, Robinson, B. Liang Y.-C, Polasky, S., Ma, D.-C, Wang, F.-C, Ruckelshaus, M., Ouyang, Z.-Y., Daily, G.C., 2013. The benefits, costs, and livelihood implications of a regional PES (payment for ecosystem service) program. Proc Natl. Acad. Sci. 110 (41), 16681-16686. 